\title{
EMPIRICAL ANALYSIS ON CORPORATE TRANSPARENCY, COMPETITIVE ADVANTAGE, AND FIRM PERFORMANCE: AN INSIGHT OF MUSCAT SECURITIES MARKET
}

\author{
Ashrf Alzman Mohammed Osman Gani1, Essia Ries Ahmed ${ }^{1},{ }^{*}$ Abdul Hamid Said Salim Al Rahbi ${ }^{1}$ \\ ${ }^{1}$ Collage of Economics, Management and Information Systems, University of Nizwa, Oman
}

ABSTRACT - The primary purpose of this study is to define the relationship between corporate transparency and firm performance. This study also elucidates the relationship between competitive advantage and company performance. A sample size of 60 was selected from three sectors (Financial, Industrial, and Service) in the Muscat Securities Market (MSM), and the collected secondary data was examined using the Smart PLS 3.0. The findings revealed that an significant positive association between corporate transparency and firm performance. The findings confirmed that corporate transparency is positively related to performance, enhancing managerial accounting measurements. Therefore, corporate transparency is an essential tool towards maintaining a competitive advantage and enhancing company's financial performance. The findings confirmed that most companies in Oman have excellent disclosure of financial statement transparency but are less socially transparent.

\author{
ARTICLE HISTORY \\ Received: $17-2-2021$ \\ Revised: 22-4-2021 \\ Accepted: 17-5-2021 \\ KEYWORDS \\ Corporate Transparency, \\ Competitive Advantage, \\ Performance, \\ Oman
}

\section{INTRODUCTION}

Transparency is a business enterprise's most significant untapped competitive benefit (Gorsht, 2014), defined as the lack of unseen information (Kirby, 2012). It is no longer a choice but a necessity in the $21^{\text {st }}$ century (Gek, Lok, 2019). A company's transparency strategy is designed to improve its financial standing (Soppe, Zijl \& Bos, 2010; Chiang \& He, 2003; Mitton, 2002; Diamond \& Verrecchia, 1991). Commercial transparency increases customer pride or value, client enchantment, and competitive position, i.e., transparent agencies are coveted by clients, while those that are less transparent are not (Singh, Islam, Ahmed \& Amran, 2019; Schulte, Rottke \& Pitschke, 2005). A study investigates the latest growths in the competition concept such as Resource Advantage (Hunt \& Morgan, 1995). Recognizing the importance of company transparency and aggressive advantage, it is critical to elucidate whether or not transparency practices are linked with performance in the Omani context.

Company transparency is essential to competitive advantage and performance (Hao, Ahmed, Singh, \& Amran, 2019). It also increases job satisfaction among employees (Zakutnia, 2017). Balmer and Gray (1999) demonstrated the value of company communication and how it facilitates competitive advantage. Corporate transparency acts as a subset of company communication, while competitive advantage is reflected in an organization's ability to create and compete, culminating in corporate profitability (Zainul, Astuti, Arifin, \& Utami, 2016; Zakutnia, 2017).

Generally, corporate transparency is risk-prone (Eldomiaty, 2009). There are organizational risks tied to corporate performance and competitive advantage, linked to non-company employees. For example, some industrial companies in Oman and the Arabian Gulf face risks and pressures brought on by the environment (Alabdullah, Ahmed, \& Ahmed, 2021; Hashim, Ries, \& Huai, 2019; Gek, Lok, 2019). The main objective of this study is to determine the effect of corporate transparency (Corporate and Strategic Information, Financial and Capital Market Information, ForwardLooking Information, Corporate Social Responsibility Information) on Omani companies performance in light of competitive advantage; especially publicly listed firms in Muscat Securities Market (MSM) with reported decreased transparency and performance.

\section{LITERATURE REVIEW}

\section{Related Work-Corporate Transparency}

This study utilized previous studies in the literature, where most agreed that corporate transparency impacts company performance. Al-Ahdal, Alsamhi, Tabash, and Farhan (2020) analyzed the effect of corporate governance mechanisms on the financial version of GCC and Indian listed firms and confirmed that board accountability (BA) and audit committee (AC) has a trivial impact on organizational performance, as measured by Tobin's Q and ROE, while transparency and disclosure (TD) harm organizational performance, as measured by Tobin's Q. Li, Miao, Zheng, and Tang (2019) investigated the link between overall transparency and corporate performance, and they posited a negative relationship between general transparency and the implementation of companies. Using census data of 2018, they proved that this relationship is due to increased transparency decreasing the performance of companies in general. The study also included 
the positive and negative influences on the relationships between transparency and company performance between countries, while detailing the direct impact of general transparency on job work in companies. López-Arceiz, BellostasPérezgrueso, Moneva-Abadía, and Rivera-Torres, (2018) analyzed the transparency mechanism alongside excellent corporate governance practices for socially responsible firms and its effect on the financial performance of the companies. They reported that the firms should develop the methods of CG with a high level of transparency and disclosure. Hassouna, Doda, and Hassoiney (2017) reported the lack of a relationship between transparency and company performance in Egypt. They utilized data from 45 companies during 2006 - 2010 for their study. They noted that the relationship between general transparency and company performance is negligible, and that there is no direct impact between general transparency and company performance. Domindern (2018) studied the relationship between general transparency and company performance and posited that it is positive in providing the employees with the tools required to improve their job performance. The study agreed with previous ones conducted in 2012 and 2008 utilizing data from companies in the Arabian Gulf by Pugach and Warr. Arsov and Vesan (2017) analyzed companies in the Arab world and confirmed that general transparency and company performance are positively related and that financial disclosure can identify future and potential problems. Also, experiences of companies during 2000, 2005, and 2009 proved that it is associated with the satisfaction of investors, as it makes them more credible. However, this relationship has one problem: the company's disclosure leads to different opinions and understandings of its plan. Gek and Lok (2019) posited that if the project for which the information was provided has been completed, and the extra profits and how they spend their capitals is disclosed, the investors will be more confident vis-à-vis the company, which will compel them to buy more shares, translating into higher share prices.

\section{Related Work-Competitive Advantage}

The competitive advantage concept has long occupied one of the central positions in the field of strategical governance. In 1937, Alderson suggested that a fundamental aspect of competitive adaptation is the specialization of suppliers in meeting variations in buyers' demand (Hoffman 2000). Competitive advantage can be maintained by offering superior value to stakeholders by maintaining long-term partner relationships either upwards to suppliers or downwards to customers in the channel. Most studies confirmed that competitive advantage impacts company performance. Al Badi (2018) examined marketing combination (place, price, product, promotion, and price) on realizing the competitive advantage in the medium and small enterprise (SME) in the Al Buraimi Governorate in the Sultanate of Oman. They reported that all of the marketing combination basics (place, price, product, promotion, and price) have essential impacts towards achieving competitive advantage in Al Buraimi's SMEs. Sazegar, Forouharfar, Hill, Faghih (2018). The other example is elucidating the innovation-based aggressive benefits of Oman's economy; then evaluate Sultanate of Oman alongside Qatar as per the Global Innovation Index's (GII) sub-indices. After processing the data, the SWOT (Weaknesses, Strengths, Opportunities, and Threats) evaluation of the Sultanate of Oman relative to Qatar would be used to develop a reference point. The findings confirm that the Sultanate of Oman ranks close to Qatar in institutional components and not so close to Qatar in terms of substructure indices. The evaluation of innovationbased aggressive gain is embraced and longitudinal to the extent of 2009 - 2017. The lookup inference is that the formulated techniques ought to be utilized by Omani decision-makers for entrepreneurship, which would consequently enhance the welfare in the Sultanate of Oman (The social implication is that it improves the Sultanate of Oman financial system via high-quality entrepreneurship). The uniqueness of this paper is predicated upon its utilization of GII sub-indices for the first period to formulate administrative techniques to advertise entrepreneurship in the Sultanate of Oman.

Al-Mascati and Al-Badi (2016, March) posited that CSFs are crucial to the success of cloud computation acceptance in oil and gasoline enterprises in Oman. They reported that the pinnacle 5 elements affecting cloud computing approval are the provider providers' support, comprehensive telecom services, pinnacle administration support, and monetary incentives. However, it should be pointed out that statistics safety and regulatory surroundings do not affect adoption.

Bakri (2017) analyzed the relations between internet-based competitive advantage and social media in SMEs in the travel, restaurants, and resorts zone in an area using structural equivalence modeling and confirmatory element analysis. They reported no significant relationships between competitive advantage and social media use. Only 10\% of SMEs use social media, and of these, $72 \%$ use Facebook, 27\% Twitter, and 1\% YouTube. Social media increased patron carrier and relations, and $80 \%$ stated it had multiplied merchandise and service. Uncertainty in using social media, measuring the reappearance of funding, and persuading personnel to embody social media are challenges.

Onour and Abdo (2020) analyzed the competitive advantage gained by large-sized banks in the Gulf Cooperation Council (GCC) countries. They adopted quintile and logistic regression analysis to investigate the association between return to scale and profitability using data for 81 (the year 2016) and 84 (the year 2015) banks operating in GCC countries. Their findings indicate a positive association between bank size and increasing return to scale, which means that bigger banks show increasing return to scale, but with decreasing rates, as represented by the negative coefficient of the square of the asset variable. Their results also show that medium and upper quintile of profits is significantly associated with assets but negatively associated with deposits, implying that banks with more significant deposits face liability management problems. Generally, the results support the evidence that large-sized banks in GCC countries have competitive advantage gains over small-sized banks. Still, the competitive advantage is inversely related to bank sizes. 
The basic argument for competitive advantage means that when a firm's profit rate is higher than the industry average, it has a "sustained competitive advantage" if this profit rate remain sustainable over the years. The essential criteria for competitive advantage are the amount of value customers place on the firm's goods or services that must exceed the cost of production.

\section{Relationship between Corporate Transparency and Firm Performance}

Al-Ahdal et al. (2020) reported that audit committee (AC) and board accountability (BA) have insignificant impacts on companies' performance measured by Tobin's Q and ROE. Similarly, transparency and disclosure (TD) have a minor negative impact on firms' performance as measured by Tobin's Q. Li, Miao, Zheng, and Tang (2019) reported a negative relationship between general transparency and company performance as per data from the 2018 census, the reason being that with increasing clarity, the company performance decreases (generally). Thus, Zarahazalose and Moneva (2017) posited that transparency and company performance is positively correlated, where transparency helps a company. Domindern (2018) outlined that the relationship between general transparency and company performance is positive in providing employees with the tools needed to increase their job performance. Arsov and Vesan (2017) believe transparency and company performance is positively correlated, while Rink (2020) posited that transparency significantly improves company performance and increases financial liquidity. Therefore, the following hypothesis was developed:

H1: A positive relation between transparency and firm performance.

\section{Relationship between Competitive Advantage and Firm Performance}

Al Badi (2018) posited that the outcomes expression of all marketing combination elements (place, price, product, promotion, and price) affects the realization of competitive advantage in Al Buraimi's SMEs. Al-Mascati and Al-Badi (2016) analyzed the effect of CSFs on the acceptance of cloud computing. They reported that the top five elements affecting cloud computing adoption are the carrier providers' support, good telecom services, pinnacle administration support, and economic incentives. Bakri (2017) mentioned that the effects confirmed no significant relationships between competitive advantage and social media usage. Onour and Abdo (2020) also reported that medium and upper quintile of profits is significantly associated with assets but negatively associated with deposits, implying that banks with more significant deposits face liability management problems. Thus, the developed hypothesis becomes:

H2: A negative relation between Competitive Advantage and company performance.

\section{METHODOLOGY}

This is cross-sectional research using the quantitative approach, where the quantitative data was accumulated via secondary data. This study population consists of public recorded businesses listed on the Muscat Securities Market (MSM) for end-of-year 2019. The sample size is 60 companies from the (Financial, Industrial, and Service) sectors selected due to its importance to the Omani economy.

Table 1. Sample Size

\begin{tabular}{lll}
\hline Sector & Companies & Sample \\
\hline Financial & 36 & 20 \\
Industrial & 40 & 20 \\
Service & 40 & 20 \\
Total & 116 & 60
\end{tabular}

\section{Measurement of Variables}

This study utilized a broad range of measurements to measure its elected variables within corporate transparency, competitive advantage, and firm performance. Each variable is clarified in Table 2:

Table 2. Summary of variables measurements

\begin{tabular}{|c|c|}
\hline Variables & Description \\
\hline \multirow[t]{3}{*}{ Corporate Transparency (CT) } & $\begin{array}{l}\text { Divided into four sub-indices, namely financial transparency, } \\
\text { governance transparency, and social transparency. } \\
\text { Annual reports were scrutinized to obtain the index, and the formula } \\
\text { is as followed } \\
\text { Actual number of disclosed items }\end{array}$ \\
\hline & Disclosure Index $=$ \\
\hline & Maximum possible disclosure items \\
\hline Competitive Advantage (CA) & $\begin{array}{l}\text { Generate greater sales or margins and/or retain more customers than } \\
\text { its competition. }\end{array}$ \\
\hline Return on Asset (ROA) & Net Income After Taxes / Total Assets \\
\hline
\end{tabular}




\begin{tabular}{cc}
\hline Variables & Description \\
\hline Return on Equity (ROE) & Net Income After Taxes / Total Equity \\
\hline
\end{tabular}

\section{Descriptive Statistics}

Based on the outcomes of the descriptive statistics, the dependent variable, firm performance (ROE and ROA), displayed a level of ROA of $0.6 \%$ on behalf of the average of company's performance, with a standard deviation of 0.111 . Also, the maximum and minimum value of the ROA is $16 \%$ and $69.0 \%$, respectively. Similarly, the outcomes displayed a level of ROE of $13.8 \%$, representing the average of company performance, with a standard deviation of 0.411 . The minimum and maximum values indicated that ROE is $-48 \%$ and $2.9 \%$, respectively. The expressive investigation for factors displays that corporate transparency has an average of $2.8 \%$, with a standard deviation of 2.174; the competitive advantage has an average of $3.2 \%$, with a standard deviation of 7.872 .

Table 3. Descriptive Statistics of variables

\begin{tabular}{ccccc}
\hline & Mean & Minimum & Maximum & Standard-D \\
\hline ROA & 0.069 & -0.160 & 0.690 & 0.111 \\
ROE & 0.138 & -0.480 & 2.960 & 0.411 \\
CT & 2.884 & 0.100 & 9.400 & 2.174 \\
CA & 3.288 & -3.000 & 9.800 & 7.872
\end{tabular}

\section{Discriminant Validity}

Requirements govern the PLS check for discriminant rationality. The square-root of each AVE for each assemble ought to have an excessive correlation stage alongside the different constructs. Thus, to agree with discriminant rationality, as per Fornell \& Larcker (1981), the rectangular root of every assemble in the AVE has to be in contrast to the constructs' links in the case of all different constructs.

Table 4. Discriminant Validity Constructs

\begin{tabular}{lllll}
\hline & CA & CT & ROA & ROE \\
\hline CA & 1.00 & & & \\
CT & 0.121 & 1.000 & & \\
ROA & 0.030 & 0.560 & 1.000 & \\
ROE & 0.037 & 0.119 & 0.226 & 1.000
\end{tabular}

The estimation for the Structural-model used to be achieved after dimension mannequin evaluation, and it surpassed all criteria. The dedication coefficient $\left(\mathrm{R}^{2}\right)$ was calculated. An endogenous variable has an $\mathrm{R}^{2}$ of $0.315(\mathrm{ROA}), 0.015$ (ROE) (significant), signifying that $31 \%, 1 \%$ of the variance in firm performance (ROE and ROA) can be clarified using the analysts' corporate transparency (Divided into four sub-indices namely social transparency, financial transparency, and governance transparency) and the competitive advantage (Generate more significant sales or margins and/or retain more clients than its competition): It can therefore be surmised that this work meets the standards.

Table 5. Explanation of the Variance

\begin{tabular}{|c|c|c|}
\hline Matrix & R Square & R Square A \\
\hline Exogenous Variables -> Endogenous (ROA) & 0.315 & 0.291 \\
\hline Exogenous Variables -> Endogenous (ROE) & 0.015 & -0.019 \\
\hline
\end{tabular}

\section{Path Coefficients}

Table 6 shows the assessments of the fall-outs linked to challenging the hypothesis. It was found that three of the hypotheses are unsupported and another one of the hypotheses supported (Only one hypothesis supported as exposed in Table 6). The findings revealed that corporate transparency is positively insignificant with firm performance (ROE), where it is $\mathrm{P}<0.05, \mathrm{t}=0.484$, confirming the considerable not impact of corporate transparency on firm performance (ROE). Corporate transparency has a significant positive relationship with a firm performance (ROA), where it is $\mathrm{P}<0.05$, $\mathrm{t}=0.4 .577$, confirming the considerable impact of corporate transparency on firm performance (ROA). This result indicates that the corporate transparency has a significant effect on performance (ROA). 
Table 6. Path Coefficients

\begin{tabular}{lcccccc}
\hline & $\begin{array}{c}\text { Original } \\
\text { Sample }\end{array}$ & $\begin{array}{c}\text { Sample } \\
\text { Mean (M) }\end{array}$ & $\begin{array}{c}\text { Standard } \\
\text { Deviation }\end{array}$ & $\begin{array}{c}\text { T } \\
\text { Statistics } \\
(\text { O/STDEV })\end{array}$ & P Values & Result \\
\hline CA -> ROA & -0.038 & -0.032 & 0.063 & 0.598 & 0.550 & Rejected \\
CA -> ROE & 0.023 & 0.028 & 0.151 & 0.151 & 0.880 & Rejected \\
CT-> ROA & 0.565 & 0.561 & 0.123 & 4.577 & 0.000 & Accepted \\
CT-> ROE & 0.116 & 0.202 & 0.240 & 0.484 & 0.628 & Rejected
\end{tabular}

Note: Significance levels: $* * * \mathrm{P}<0.001(\mathrm{t}>3.33),{ }^{* *} \mathrm{p}<0.01(\mathrm{t}>2.33),{ }^{*} \mathrm{p}<0.05(\mathrm{t}>1.605)$

\section{IMPACT OF CORPORATE TRANSPARENCY AND COMPETITIVE ADVANTAGE ON FIRMS PERFORMANCE}

This study analyzes the relationship between competitive advantage and corporate transparency alongside firm performance in the MSM of the Sultanate of Oman. The objective is to analyze and comprehend the relationship between competitive advantage and corporate transparency with firm performance in the Sultanate. Looking into previous works, two variables were determined to affect performance, which was independent variables competitive advantage (sales or margins and/or retain) and corporate transparency (financial transparency, governance transparency, and social transparency). From the wholly recognized independent variables, hypotheses were formed addressing the goals. The study used the quantitative data from the (Financial, Industrial, and Service) sectors on the MSM website for 2019. 60 out of 116 firms were successfully analyzed.

Competitive Advantage: One of the independent variables is associated with a competitive advantage and company performance. The outcomes show a insignificant negative relationship between competitive advantage and $\mathrm{ROA}(\mathrm{p}<0.05$, $\mathrm{t}=0.598)$. The results also show a insignificant positive link between competitive advantage and $\operatorname{ROE}(\mathrm{p}<0.05, \mathrm{t}=0.151)$. The results are consistent with Bakri (2017), who posited that the relationship between certain variables and competitive advantages is insignificant. The Omani scene is less competitive, and it can be surmised that increased competition within the Omani market would result in better overall performance by the companies.

Corporate Transparency: One of the independent variables is associated with corporate transparency and firm performance. The results show a significant positive association between corporate transparency and ROA ( $<<0.05$, $\mathrm{t}=4.577$ ). The results also show a insignificant positive relationship between corporate transparency and $\mathrm{ROE}(\mathrm{p}<0.05$, $\mathrm{t}=0.628$ ). This finding depends on Domindern (2018), who posited that general transparency positively influences company performance. López-Arceiz, Francisco José, et al. (2018) also reported that the relationship between transparency and company performance is positive. Higher transparency leads to higher performance (of companies) due to its directly proportional relationship. However, a probable cause for a significant finding of the transparency on performance is that corporate translucence of Omani firms are taken as important as .compared with corporate transparency of other firms in the world Further, the study indicates that proper implementation of the corporate transparency mechanism leads to improves the organization's profitability. Thus, this improved performance will positively improve the Omani economy in the long run.

\section{Recommendation}

This study examined the direct relationship between competitive advantage, corporate transparency, and firm performance. No previous works explore the impact of the relationship between competitive advantage, corporate transparency, and understanding that would lead to increased company performance. Future research can analyze the relationship between social transparency and company performance due to the limited social transparency. Researchers could also explore the relationship between corporate transparency, competitive advantage, and performance via new variables such as auditing reports. Governments should pressure companies to make more disclosures in social transparency. It is also recommended that researchers analyze corporate transparency and competitiveness in the GCC countries or compare the factors in Oman to that of the UAE.

\section{CONCLUSION}

The main objective of this study is to analyze the relationship between competitive advantage and corporate transparency with firm performance to improve the profitability of companies based in the Sultanate of Oman. This study used two independent variables (corporate transparency and competitive advantage) to measure the impact of corporate transparency and competitive advantage tools on firm performance (ROA and ROE).

The findings confirmed that high transparency resulted in increased company performance, which means that it is essential that managers select and implement strategies that would result in good governance, transparency, and integrity. Most companies in Oman have excellent financial statement transparency, but this practice in corporate governance is mediocre. The method of disclosing social transparency is even lower. The research helped us understand corporate transparency and tools for competitive advantage influencing the performance of Omani companies. Not all firms reported similar outcomes. Some firms perform better due to better disclosure practices, which is a positive practice. 
In some cases, it could result in negative results, mostly from limited disclosure and data ambiguity. Company performance was low via the ROA and ROE. Data from 60 firms were analyzed from various sectors (financial, industrial, and service) listed in the MSM. Corporate governance and strategic disclosure were the most dominant, meaning that companies in Oman should divulge more information in this area. This study will give users and investors aware of impacts of corporate transparency features' on the firm performance.

\section{ACKNOWLEDGEMENT}

The authors would like to thank the University of Nizwa and Dr. Essia Ries Ahmed which assist to conduct this research.

\section{REFERENCES}

Alabdullah, T. T. Y., Ahmed, E. R., \& Ahmed, R. R. (2021). Organization features and profitability: Implications for a sample of Emerging Countries. JABE (Journal of Accounting and Business Education), 5(2), 43-52.

Al-ahdal, W. M., Alsamhi, M. H., Tabash, M. I., \& Farhan, N. H. (2020). The impact of corporate governance on financial performance of Indian and GCC listed firms: An empirical investigation. Research in International Business and Finance, 51, 101083.

Al-Mascati, H., \& Al-Badi, A. H. (2016, March). Critical success factors affecting the adoption of cloud computing in oil and gas industry in Oman. In $20163 \mathrm{rd} \mathrm{MEC} \mathrm{International} \mathrm{Conference} \mathrm{on} \mathrm{Big} \mathrm{Data} \mathrm{and} \mathrm{Smart} \mathrm{City} \mathrm{(ICBDSC)} \mathrm{(pp.} \mathrm{1-7).} \mathrm{IEEE.}$

Al Badi, K. S. (2018). The impact of marketing mix on the competitive advantage of the SME sector in the Al Buraimi Governorate in Oman. SAGE Open, 8(3), 2158244018800838.

Al-Mascati, H., \& Al-Badi, A. H. (2016, March). Critical success factors affecting the adoption of cloud computing in oil and gas industry in Oman. In 20163 rd MEC International Conference on Big Data and Smart City (ICBDSC) (pp. 1-7). IEEE.

Arsov, S., \& Bucevska, V. (2017). Determinants of transparency and disclosure-evidence from post-transition economies. Economic research-Ekonomska istraživanja, 30(1), 745-760.

Bakri, A. A. A. (2017). The impact of social media adoption on competitive advantage in the small and medium enterprises. International Journal of Business Innovation and Research, 13(2), 255-269.

Balmer, J.M.T. \& Gray, E.R. (1999). Corporate identity and corporate communications: creating a competitive advantage, Corporate Communications: An International Journal, 4(4), 171- 177.

Chiang, H., \& He L., (2003); Corporate Transparency and Operating Performance, Allied Academies International Conference, 35.

Diamond, D. W., \& Verrecchia, R. E. (1991). Disclosure, liquidity, and the cost of capital. The journal of Finance, 46(4), 1325-1359.

Eldomiaty, T. I. (2009). The fundamental determinants of systematic risk and financial transparency in the DFM General Index. Middle Eastern Finance and Economics, (5).

Gek, C. M., \& Yap Peng Lok, S. (2019). Corporate transparency, competitive advantage and firm performance: Evidence from public listed firms in Malaysia. Global Business \& Management Research, 11(2), 73-81.

Gorsht, R (2014), Transparency: The New Competitive Advantage, Forbes.

Hao, Y. Ahmed, E. R, Singh, K. S. D., \& Amran, A. (2019) Innovation and diversity based organization culture and its effect on competitive advantage, Opción, Vol 35(21),1205-1216.

Hashim, F., Ries, E. A., \& Huai, N. T. (2019). Corporate Social Responsibility and Financial Performance: The Case of ASEAN Telecommunications Companies. KnE Social Sciences, 892-913.

Hassouna, D., Ouda, H., \& Hussainey, K. (2017). Transparency and disclosure as a corporate governance mechanism and corporate performance: Egypt's case. Corporate Ownership and Control, 14(4), 182-195.

Hunt, S. D., \& Morgan, R. M. (1995). The comparative advantage theory of competition. Journal of marketing, 59(2), 1-15.

Kirby, J (2012, July) . Trust In The Age Of Transparency, Harvard Business Review.

Li, Y., Miao, X., Zheng, D., \& Tang, Y. (2019). Corporate public transparency on financial performance: The moderating role of political embeddedness. Sustainability, 11(19), 5531.

López-Arceiz, F. J., Bellostas-Pérezgrueso, A. J., Moneva-Abadía, J. M., \& Rivera-Torres, M. P. (2018). The role of corporate governance and transparency in the generation of financial performance in socially responsible companies. Spanish Journal of Finance and Accounting/Revista Española de Financiación y Contabilidad, 47(1), 44-80.

Mitton, T. (2002). A cross-firm analysis of the impact of corporate governance on the East Asian financial crisis. Journal of financial economics, 64(2), 215-241.

Onour, I. A., \& Abdo, M. M. (2020). Assessing Competitive Advantage of Banks in GCC Countries. Manag Econ Res J, 6(2), 12726.

Sazegar, M., Forouharfar, A., Hill, V., \& Faghih, N. (2018). The innovation-based competitive advantage in Oman's transition to a knowledge-based economy: dynamics of innovation for promotion of entrepreneurship. In Entrepreneurship Ecosystem in the Middle East and North Africa (MENA) (pp. 491-518). Springer, Cham.

Schulte, K.W., Rottke, N., \& Pitschke, C. (2005), "Transparency in the German real estate market", Journal of Property Investment and Finance, Vol. 23 No. 1, 90-108.

Singh, K. S. D., Islam, M. A., Ahmed, E. R., \& Amran, A. (2019) An empirical investigation into the major drivers of corporate social responsibility.Opción, Año 35, Especial No.21 (2019): 1076-1090.

Soppe, A., Van Zijl, N., \& de Bos, A. (2012). Board transparency, CEO monitoring and firms' financial performance. In Transparency and Governance in a Global World. Emerald Group Publishing Limited.Vol. 13), Emerald Group Publishing Limited, Bingley, pp. 99-125.

Zakutnia, A. O., \& Hayriyan, A. (2017). Transparency as competitive advantage of innovation driven companies.Business Ethics and Leadership, Volume 1, Issue 1, 46-54.

Zainul, M., Astuti, E. S., Arifin, Z., \& Utami, H. N. (2016). The effect of market orientation toward organizational learning, innovation, competitive advantage, and corporate performance (A study at SME Sasirangan in South Kalimantan). Journal of Administrative Sciences and Policy Studies, 4(1), 1-19. 


\section{CONFLICT OF INTEREST}

The author(s), as noted, certify that they have NO affiliations with or involvement in any organisation or agency with any financial interest (such as honoraria; educational grants; participation in speakers' bureaus; membership, jobs, consultancies, stock ownership, or other equity interest; and expert testimony or patent-licensing arrangements), or nonfinancial interest (such as personal or professional relationships, affiliations, expertise or beliefs) in the subject matter or materials addressed in this manuscript.

\section{AUTHORS' BIOGRAPHY}

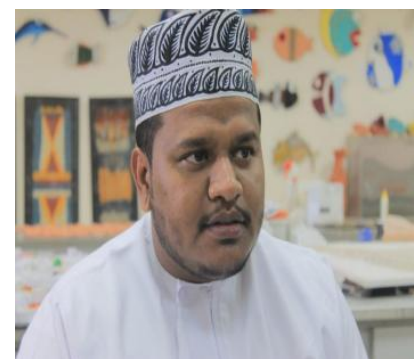

Ashrf Alzman Mohammed Osman Gani is a bachelor student in College of Economics, Management and Information Systems, University of Nizwa. The author is interested in auditing, and accounting research areas.

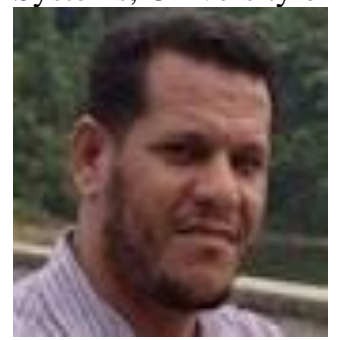

Dr. Essia Ries Ahmed is currently working as an assistance of Professor in University of Nizwa. He received his PhD from University Malaysia Perlis (UniMap), master's degree in Accounting from Universiti Sains Malaysia (USM). He has published articles in several Scopus Journals, and proceedings and presented papers at both national and international conferences. Dr. Essia Ries Ahmed is the reviewer and member of editorial board in several journals.

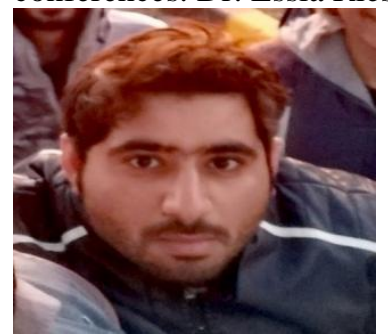

Abdul Hamid Said Salim Al Rahbi is a bachelor student in College of Economics, Management and Information Systems, University of Nizwa. The author is interested in auditing, and accounting research areas. 